\title{
Does increased body mass index lead to elevated prostate cancer risk? It depends on waist circumference
}

\author{
Jin Bong Choi ${ }^{1 \dagger}$, Jun-Pyo Myong ${ }^{2 \dagger}$, Yunhee Lee ${ }^{2}$, Inah $\mathrm{Kim}^{3}$, Jung Ho Kim${ }^{4}$, Sung-Hoo Hong ${ }^{5}$ and U-Syn Ha ${ }^{5^{*}}$
}

\begin{abstract}
Background: We examined the association between obesity and prostate cancer based on both body mass index (BMI) and waist circumference (WC) using the National Health Insurance System (NHIS) database for the entire male population of Korea.

Methods: A total of 1,917,430 men who underwent at least one health examination in 2009 without a previous diagnosis of any other cancer were tracked through December 2015. The hazard ratio (HR) and 95\% confidence interval (Cl) value for the association between prostate cancer and obesity were analyzed using multiple Cox regression model. Since there was a statistically significant interaction between WC and BMI, a multiple HR for prostate cancer was estimated with stratifying both WC and BMI to control the interaction between WC and BMI.

Results: Without considering WC as an adjustment factor, very weak association between BMI and prostate cancer development risk was observed. When WC was considered as an adjustment factor, no significant change in the HRs for prostate cancer development beyond the reference BMI was observed in the group with $W C<85 \mathrm{~cm}$ in the multivariable-adjusted models. However, in the group with $W C \geq 85 \mathrm{~cm}$, the HRs for prostate cancer increased as the BMI increased beyond the reference BMI. In addition, there was a discrepancy in the trend of prostate cancer development according to BMI among the groups with different categories for WC.

Conclusion: In groups with abdominal obesity, a significant linear relationship was observed between increasing $\mathrm{BMI}$ and prostate cancer risk. Higher the WC category, the stronger was the association with BMI, signifying that the association of BMI with risk of prostate cancer development depends on abdominal obesity.
\end{abstract}

Keywords: Prostate cancer, Obesity, Waist circumference

\section{Background}

Prostate cancer is the second most common cancer in men worldwide and the third most commonly occurring cancer in both the sex according to GLOBOCAN 2018 $[1,2]$. Though African-American men have still the highest incidence rate, a constant increase has been

\footnotetext{
* Correspondence: ushamd@catholic.ac.kr

${ }^{\dagger}$ Jin Bong Choi and Jun-Pyo Myong contributed equally to this work. ${ }^{5}$ Department of Urology, Seoul St. Mary's Hospital, College of Medicine, The Catholic University of Korea, 222, Banpo-daero, Seocho-gu, Seoul 06591, South Korea

Full list of author information is available at the end of the article
}

reported in many Asian countries [3]. In Korea, the agestandardized rate for prostate cancer incidence has increased by $0.2 \%$ annually from 1999 to 2016 [4]. Therefore, prostate cancer can be considered to one of the most important male cancers in Korea.

This increasing trend may partly be explained by rapid population aging, westernized dietary habits, and increased prostate-specific antigen (PSA) screening [5]. In addition to these risk factors, obesity, which showed an upward trend among men, has been reported as a highrisk factor of prostate cancer in Korea [6]. Associations

(c) The Author(s). 2020 Open Access This article is licensed under a Creative Commons Attribution 4.0 International License, which permits use, sharing, adaptation, distribution and reproduction in any medium or format, as long as you give appropriate credit to the original author(s) and the source, provide a link to the Creative Commons licence, and indicate if changes were made. The images or other third party material in this article are included in the article's Creative Commons licence, unless indicated otherwise in a credit line to the material. If material is not included in the article's Creative Commons licence and your intended use is not permitted by statutory regulation or exceeds the permitted use, you will need to obtain permission directly from the copyright holder. To view a copy of this licence, visit http://creativecommons.org/licenses/by/4.0/. The Creative Commons Public Domain Dedication waiver (http://creativecommons.org/publicdomain/zero/1.0/) applies to the data made available in this article, unless otherwise stated in a credit line to the data. 
between obesity and prostate cancer risk have also been analyzed in multiple studies worldwide [7-10]. However, these studies have varied substantially in their results depending on the research methods used.

The existing discrepancies might be because most of the studies used body mass index (BMI) to analyze the relationship between obesity and prostate cancer. Though BMI provides the most common estimate of obesity in cancer epidemiologic studies, it does not measure adipose mass sufficiently [11]. Especially in men, BMI correlates better with lean mass than with body adiposity, and it is hypothesized that metabolically obese but normal-weight (MONW) individuals might have a normal BMI [12].

Consequently, other measures that could capture centralized fat disposition such as waist circumference (WC) should be estimated in combination with BMI when considering obesity as a risk factor for prostate cancer development. Therefore, in this study, we examined the association between obesity and prostate cancer based on both BMI and WC using the National Health Insurance System (NHIS) database for the entire male population of Korea.

\section{Methods}

\section{Data source}

The NHIS database of Korea is a public database comprising of the eligibility database, the national health screening database, the health care utilization database, and the long-term care insurance database [13]. This database includes the insurance claim code based on the International Classification of Diseases, 10th Revision, Clinical Modification (ICD-10-CM). Prostate cancer is coded C61. To identify clearly the diagnosis of prostate cancer, patients who had not undergone trans-rectal prostate biopsy were excluded from the study. In addition, the national health screening database was used to obtain information about WC, BMI, and other variables (hypertension, diabetes, dyslipidemia, alcohol consumption status, and smoking status).

The definition of measurements including categories for WC and BMI has been described in previous study using the NHIS database as follows: 1) WC cutoff value for abdominal obesity: $\geq 90 \mathrm{~cm}$ for men, 2) BMI categories: underweight (under 18.5), normal weight (18.5 to 22.9 ), overweight (23 to 24.9 ), obese class 1 (25 to 29.9 ), obese class 2 (over 30), 3) Hypertension: diagnostic code I10-15, blood pressure $\geq 140 / 90 \mathrm{mmHg}$, or history of taking antihypertensive drugs, 4) Diabetes: diagnostic code E10-14, fasting serum glucose level $\geq 126 \mathrm{mg} / \mathrm{dl}$, or self-reported medical history of diabetic drugs, and 5) Dyslipidemia: diagnostic code E78, total cholesterol level $\geq 240 \mathrm{mg} / \mathrm{dl}$, or self-reported use of lipid-lowering drugs [14].

\section{Study population}

Of the 5,860,389 men who underwent at least one health examination in 2009, men with prostate cancer or other cancers diagnosed before $1^{\text {st }}$ January $2009(n=253,157)$ were excluded. Moreover, patients aged $<50$ years $(n=3$, $684,955)$ were excluded because prostate cancer is rare in this age group. After excluding people with missing WC or BMI data from health examination databases $(n=4847)$, a total of $1,917,430$ men without a previous diagnosis of any other cancer were tracked through $31^{\text {th }}$ December 2015. The study design and disposition of the subjects are shown in Fig. 1.

\section{Statistical analysis}

The baseline characteristics of subjects have been presented as the number (\%) for categorical variables. Incidence rate is expressed as the number of newly diagnosed cases of prostate cancer per 100,000 person-years of the follow-up period. The hazard ratio (HR) and $95 \%$ confidence interval $(\mathrm{CI})$ value for prostate cancer of obesity were analyzed using a multiple Cox proportional hazard model. The model was adjusted for common variables such as age, diabetes, hypertension, dyslipidemia, alcohol consumption, and smoking status; the obesity indices (BMI and WC) were alternatively added on common variables for adjustment in multiple Cox proportional hazard model. There was a statistically significant interaction between WC and BMI ( $P$ value $<0.05)$. To control the interaction between WC and BMI on the incidence of prostate cancer, a multiple HR for prostate cancer was estimated with stratifying both obesity indices (WC; four classes and BMI; five classes) were classified into, respectively. Statistical significance for linear trends in the HRs for prostate cancer of BMI and WC were verified at a level of 0.05 . SAS software (version 9.4, SAS Institute, Cary, NC, USA) was used for statistical analyses.

\section{Results \\ Baseline clinical characteristics of study population according to categories for WC}

Among a total of 1,917,430 men, 22,584 (1.18\%) incident cases of prostate cancer developed between the beginning of 2009 and the end of 2015 (Table 1). Approximately $1.31 \%$ of the population categorized as $\mathrm{WC} \geq 90$ $\mathrm{cm}$ was diagnosed with prostate cancer, while $1.13 \%$ of the population categorized as $\mathrm{WC}<90 \mathrm{~cm}$ was diagnosed with prostate cancer. In the obesity group categorized as $W C \geq 90 \mathrm{~cm}, 3.05 \%$ had a normal weight according to the BMI, and $20.65 \%$ of the men categorized as the non-obesity group (WC $<90 \mathrm{~cm}$ ) were obese class 1 according to the BMI. In addition, the obesity group was more likely to have hypertension ( $54.45 \%$ vs. $36.25 \%)$, dyslipidemia ( $26.72 \%$ vs. $18.14 \%)$, and diabetes (20.65\% vs. $13.65 \%)$. 


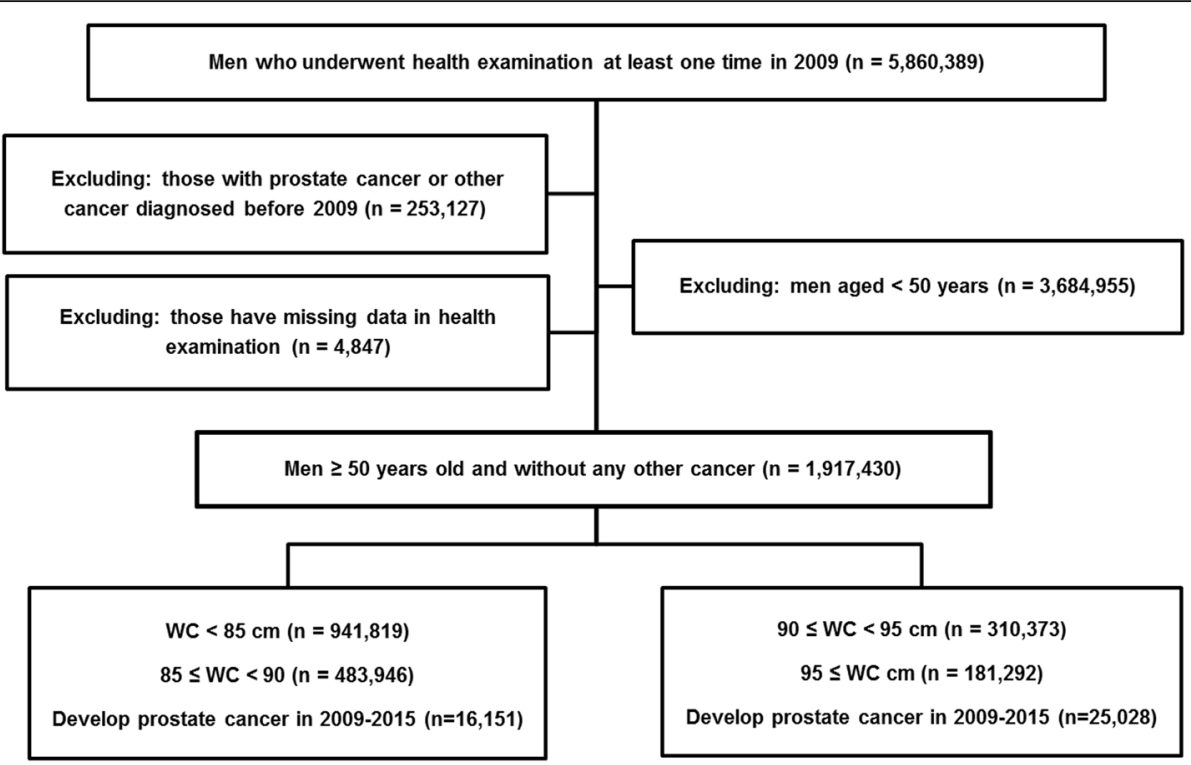

Fig. 1 Study design and disposition of subjects

\section{Risk of prostate cancer according to BMI or WC}

The HR for prostate cancer was lowest in subjects with a $\mathrm{BMI}<18.5$ and highest in those with $23.0 \leq \mathrm{BMI}<25$ in the multivariate-adjusted model (HR 0.93, 95\% CI 0.85 to 1.02 and HR 1.12, 95\% CI 1.08 to 1.16 ). However, the HRs for prostate cancer showed a decreasing trend with BMI over 25. Even in the patients with $\mathrm{BMI} \geq 30$, the $95 \% \mathrm{CI}$ reflected the relative risk of 1.00 . So, when we did not consider WC as an adjustment factor, there was a very weak association between BMI and prostate cancer development risk. The risk of prostate cancer according to WC also showed no statistically significant difference among the groups without stratification by BMI (Table 2). We also found that there was a statistically significant interaction between $\mathrm{WC}$ and BMI in this cohort $(P$ value $<0.05)$.

\section{The association between BMI and prostate cancer development according to WC}

Since there was a statistically significant interaction between WC and BMI, a multiple HR for prostate cancer was estimated with stratifying both WC and BMI to control the interaction between WC and BMI. In the group with $\mathrm{WC}<85 \mathrm{~cm}$, there was no significant change in the HRs for prostate cancer development beyond the reference BMI in the multivariable-adjusted model ( $P$ for trend $=0.158$; Table 3 and Fig. 2). The HR (95\% CI) was $1.05(1.01,1.09)$ in the overweight group, which was characterized by a BMI over 23 , and $0.99(0.92,1.07)$ in class 1 obese group, which was characterized by a BMI over 25.

However, in the groups with $\mathrm{WC} \geq 85 \mathrm{~cm}$ (groups with $85 \leq \mathrm{WC}<90,90 \leq \mathrm{WC}<95$, and $\mathrm{WC} \geq 95$ ), the HRs for prostate cancer increased as the BMI increased beyond the reference BMI ( $P$ for trend $<.001)$. In addition, there was a discrepancy in the trend of prostate cancer development according to BMI among the groups with different categories for WC (Fig. 2). The increasing rate of prostate cancer development risk according to BMI was greatest in the group with $\mathrm{WC} \geq 95$. On the other hand, HRs for prostate cancer according to WC stratified by BMI showed that impact of BMI on the risk of prostate cancer according to WC was weak (Table 4).

Figure 3 shows the HRs for prostate cancer development according to BMI (comparison of $\mathrm{BMI}<25$ and $\mathrm{BMI} \geq 25$ ) when stratified based on abdominal obesity (comparison of $\mathrm{WC}<90$ and $\mathrm{WC} \geq 90$ ). The $\mathrm{HR}$ for prostate cancer was significantly higher in $\mathrm{WC} \geq 90$ groups regardless of BMI than the reference group $(P$ value $<.001)$. However, in the $\mathrm{WC}<90$ groups, HR did not show a significant difference even if BMI was higher than $25(P$ value $=0.301)$.

\section{Discussion}

The main findings of this population-based study are (1) without considering WC as an adjustment factor, very weak association between BMI and prostate cancer development risk was observed; (2) when WC was considered as an adjustment factor, there were significant linear relations between increasing BMI and prostate cancer risk in the groups with abdominal obesity; (3) the higher the WC category, the stronger association with BMI was noted; and (4) this means that the association of BMI with risk of prostate cancer development depends on abdominal obesity. 
Table 1 Clinical characteristics of population according to WC

\begin{tabular}{|c|c|c|c|c|c|c|c|}
\hline \multirow{2}{*}{$\begin{array}{l}\text { Abdominal obesity } \\
\text { WC, cm }\end{array}$} & \multirow[b]{2}{*}{$W C<85$} & \multirow[b]{2}{*}{$\begin{array}{l}85 \leq W C< \\
90\end{array}$} & \multirow[t]{2}{*}{$\begin{array}{l}\text { Non-obesity group } \\
\text { (WC< < } 90)\end{array}$} & \multirow[b]{2}{*}{$\begin{array}{l}90 \leq W C< \\
95\end{array}$} & \multirow[b]{2}{*}{$W C \geq 95$} & \multirow[t]{2}{*}{$\begin{array}{l}\text { Obesity group }(90 \leq \\
\text { WC) }\end{array}$} & \multirow[b]{2}{*}{ Total } \\
\hline & & & & & & & \\
\hline No. in population & 941,819 & 483,946 & $1,425,765$ & 310,373 & 181,292 & 491,665 & $1,917,430$ \\
\hline $\begin{array}{l}\text { No. of diagnosed prostate } \\
\text { cancer }\end{array}$ & $10,273(1.09)$ & $5878(1.21)$ & $16,151(1.13)$ & 3989 (1.29) & $2444(1.35)$ & $6433(1.31)$ & $22,584(1.18)$ \\
\hline Age $\geq 65$ & $\begin{array}{l}266,825 \\
(28.33)\end{array}$ & $\begin{array}{l}127,838 \\
(26.42)\end{array}$ & $394,663(27.68)$ & $\begin{array}{l}88,811 \\
(28.61)\end{array}$ & $\begin{array}{l}57,504 \\
(31.72)\end{array}$ & $146,315(29.76)$ & $\begin{array}{l}540,978 \\
(28.21)\end{array}$ \\
\hline \multicolumn{8}{|l|}{$\mathrm{BMI}, \mathrm{kg} / \mathrm{m}^{2}$} \\
\hline$<18.5$ & $45,695(4.85)$ & $622(0.13)$ & $46,317(3.25)$ & 0 & 0 & 0 & $46,317(2.42)$ \\
\hline $18.5-22.9$ & $\begin{array}{l}543,779 \\
(57.74)\end{array}$ & $\begin{array}{l}79,125 \\
(16.35)\end{array}$ & 622,904 (43.69) & $12,949(4.17)$ & $2054(1.13)$ & $15,003(3.05)$ & $\begin{array}{l}637,907 \\
(33.27)\end{array}$ \\
\hline $23.0-24.9$ & $\begin{array}{l}262,548 \\
(27.88)\end{array}$ & $\begin{array}{l}199,528 \\
(41.23)\end{array}$ & $462,076(32.41)$ & $71,087(22.9)$ & $11,493(6.34)$ & $82,580(16.79)$ & $\begin{array}{l}544,656 \\
(28.41)\end{array}$ \\
\hline $25.0-29.9$ & $89,797(9.53)$ & $\begin{array}{l}204,671 \\
(42.29)\end{array}$ & $294,468(20.65)$ & $\begin{array}{l}220,303 \\
(70.98)\end{array}$ & $\begin{array}{l}132,657 \\
(73.17)\end{array}$ & $352,960(71.79)$ & $\begin{array}{l}647,428 \\
(33.77)\end{array}$ \\
\hline$\geq 30$ & 0 & 0 & 0 & $6034(1.94)$ & $\begin{array}{l}35,088 \\
(19.35)\end{array}$ & $41,122(8.36)$ & $41,122(2.14)$ \\
\hline \multicolumn{8}{|l|}{ Smoking status } \\
\hline Non & $\begin{array}{l}318,875 \\
(34.04)\end{array}$ & $\begin{array}{l}166,136 \\
(34.53)\end{array}$ & $485,011(34.01)$ & $\begin{array}{l}108,223 \\
(35.06)\end{array}$ & $\begin{array}{l}64,466 \\
(35.77)\end{array}$ & $172,689(35.12)$ & $\begin{array}{l}657,700 \\
(34.49)\end{array}$ \\
\hline Former & $\begin{array}{l}264,566 \\
(28.24)\end{array}$ & $\begin{array}{l}160,015 \\
(33.26)\end{array}$ & $424,581(29.77)$ & $\begin{array}{l}105,633 \\
(34.23)\end{array}$ & $\begin{array}{l}62,080 \\
(34.45)\end{array}$ & $167,713(34.11)$ & $\begin{array}{l}592,294 \\
(31.06)\end{array}$ \\
\hline Current & $\begin{array}{l}353,311 \\
(37.72)\end{array}$ & $\begin{array}{l}155,024 \\
(32.22)\end{array}$ & $508,335(35.65)$ & $\begin{array}{l}94,785 \\
(30.71)\end{array}$ & $\begin{array}{l}53,658 \\
(29.78)\end{array}$ & $148,443(30.19)$ & $\begin{array}{l}656,778 \\
(34.44)\end{array}$ \\
\hline Alcohol consumption & $\begin{array}{l}521,926 \\
(58.02)\end{array}$ & $\begin{array}{l}278,409 \\
(60.33)\end{array}$ & 800,335 (56.13) & $\begin{array}{l}177,492 \\
(60.04)\end{array}$ & $\begin{array}{l}101,238 \\
(58.7)\end{array}$ & $278,730(56.69)$ & $\begin{array}{l}1,079,065 \\
(58.99)\end{array}$ \\
\hline Hypertension & $\begin{array}{l}306,479 \\
(32.54)\end{array}$ & $\begin{array}{l}210,423 \\
(43.48)\end{array}$ & $516,902(36.25)$ & $\begin{array}{l}158,373 \\
(51.03)\end{array}$ & $\begin{array}{l}109,334 \\
(60.31)\end{array}$ & $267,707(54.45)$ & $\begin{array}{l}784,609 \\
(40.92)\end{array}$ \\
\hline Dyslipidemia & $\begin{array}{l}150,954 \\
(16.03)\end{array}$ & $\begin{array}{l}107,752 \\
(22.27)\end{array}$ & $258,706(18.14)$ & $\begin{array}{l}78,911 \\
(25.42)\end{array}$ & $\begin{array}{l}52,463 \\
(28.94)\end{array}$ & $131,374(26.72)$ & $\begin{array}{l}390,080 \\
(20.34)\end{array}$ \\
\hline Diabetes & $\begin{array}{l}116,357 \\
(12.35)\end{array}$ & $78,387(16.2)$ & $194,744(13.65)$ & $58,963(19)$ & $42,600(23.5)$ & $101,563(20.65)$ & $\begin{array}{l}296,307 \\
(15.45)\end{array}$ \\
\hline
\end{tabular}

Data are presented as the number (\%)

$B M I$ body mass index, WC waist circumference

Although the terms "overweight" and "obese" are similar, the difference between the two depends on the BMI. Although BMI is the most widely used method of measuring obesity, an imperfect measurement does not accurately reflect adiposity. BMI indicates overweight relative to height, but it does not discriminate between fat mass and lean body mass. Body composition is variable among individuals with the same BMI [11, 12]. Therefore, majority of the reported studies based on BMI provide an agreement that obesity is a risk factor for aggressive prostate cancer development, whereas other studies provide contrary results about localized or overall prostate cancer risk [15-17]. The inconsistent findings might be due to limitations in BMI as a calculation of adiposity.

In the present study, low WC and high BMI may be indicative of high lean body mass. In the low WC group
(WC $<85 \mathrm{~cm}$ ), adiposity of men with high BMI is expected to be smaller due to high lean body mass. Furthermore, there was a discrepancy in the trend of prostate cancer development according to BMI among the groups with different categories for WC. This finding signifies that in the higher WC group, men with high BMI have more adiposity than in the lower WC group, which increases the risk of prostate cancer development.

The distinctive feature of our study is that though few studies have simultaneously evaluated the associations between BMI, WC, and prostate cancer risk in the west $[18,19]$, to the best of our knowledge, this is the first study to evaluate the risk for patients in an Asian population with prostate cancer stratified by BMI and WC. Especially, it is noteworthy that our results are based on the Asian population. Due to ethnic differences in body composition like muscle mass and fat distribution 
Table 2 Multivariate-adjusted HRs for prostate cancer according to BMI and WC

\begin{tabular}{|c|c|c|c|c|c|}
\hline & Event & Person-years & Incidence $^{a}$ & HR (95\% confidence interval) ${ }^{b}$ & $P$ value \\
\hline \multicolumn{6}{|l|}{$\mathrm{BMl}, \mathrm{kg} / \mathrm{m}^{2}$} \\
\hline$<18.5$ & 466 & 322,751 & 144.38 & $0.93(0.85,1.02)$ & 0.143 \\
\hline $18.5-22.9$ & 7338 & $4,841,077$ & 151.57 & Ref. & \\
\hline $23.0-24.9$ & 6775 & $4,218,668$ & 160.59 & $1.12(1.08,1.16)$ & $<.001$ \\
\hline $25.0-29.9$ & 7560 & $5,039,457$ & 150.01 & $1.05(1.03,1.08)$ & 0.007 \\
\hline$\geq 30$ & 445 & 319,345 & 139.34 & $0.98(0.89,1.08)$ & 0.650 \\
\hline \multicolumn{6}{|l|}{$W C, \mathrm{~cm}$} \\
\hline$<85$ & 3833 & $7,206,600$ & 142.54 & $0.91(0.88,0.94)$ & $<.001$ \\
\hline $85-90$ & 4260 & $3,744,368$ & 156.98 & Ref. & \\
\hline $90-95$ & 4363 & $2,398,016$ & 166.34 & $0.99(0.95,1.03)$ & 0.703 \\
\hline$\geq 95$ & 716 & $1,392,314$ & 175.53 & $0.97(0.92,1.02)$ & 0.179 \\
\hline${ }^{c} p$ for interaction & $<0.05$ & & & & \\
\hline
\end{tabular}

$B M I$ body mass index, WC waist circumference, $H R$ hazard ratio

${ }^{a}$ All rates are expressed as number per 100,000 person-years

${ }^{\mathrm{b}}$ Adjusted for age, diabetes, hypertension, dyslipidemia, smoking status, and alcohol consumption

${ }^{\mathrm{c}} \mathrm{P}$ for interaction between $\mathrm{BMI}$ and WC

Table 3 Age- and multivariable-adjusted HRs for prostate cancer according to BMI stratified by WC

\begin{tabular}{|c|c|c|c|c|c|c|}
\hline \multirow[b]{2}{*}{$W C, c m$} & \multirow[b]{2}{*}{$\mathrm{BMI}, \mathrm{kg} / \mathrm{m}^{2}$} & \multirow[b]{2}{*}{ Event } & \multirow[b]{2}{*}{ Person-years } & \multirow[b]{2}{*}{ Incidence ${ }^{a}$} & \multicolumn{2}{|c|}{ HR (95\% confidence interval) } \\
\hline & & & & & Model $1^{\mathrm{b}}$ & Model $2^{c}$ \\
\hline \multirow[t]{5}{*}{$\overline{W C}<85$} & $<18.5$ & 462 & 318,733 & 144.95 & $1.06(0.96,1.16)$ & $0.95(0.87,1.05)$ \\
\hline & $18.5-22.9$ & 6033 & $4,138,307$ & 145.78 & Ref. & Ref. \\
\hline & $23.0-24.9$ & 2874 & $2,046,401$ & 140.44 & $0.97(0.93,1.02)$ & $1.05(1.01,1.09)$ \\
\hline & $25.0-29.9$ & 904 & 703,159 & 128.56 & $0.89(0.83,0.96)$ & $0.99(0.92,1.07)$ \\
\hline & $\geq 30$ & 0 & 0 & 0 & - & - \\
\hline \multirow[t]{5}{*}{$85 \leq W C<90$} & $<18.5$ & 4 & 4018 & 99.55 & $0.50(0.19,1.34)$ & $0.36(0.14,0.97)$ \\
\hline & $18.5-22.9$ & 1086 & 594,059 & 182.81 & Ref. & Ref. \\
\hline & $23.0-24.9$ & 2638 & $1,544,705$ & 170.78 & $0.95(0.88,1.02)$ & $1.13(1.04,1.21)$ \\
\hline & $25.0-29.9$ & 2150 & $1,601,586$ & 134.24 & $0.76(0.70,0.81)$ & $1.04(0.96,1.12)$ \\
\hline & $\geq 30$ & 0 & 0 & 0 & - & - \\
\hline \multirow[t]{5}{*}{$90 \leq W C<95$} & $<18.5$ & 0 & 0 & 0 & - & - \\
\hline & $18.5-22.9$ & 196 & 94,269 & 207.91 & Ref. & Ref. \\
\hline & $23.0-24.9$ & 1065 & 542,265 & 196.39 & $0.97(0.83,1.13)$ & $1.25(1.06,1.46)$ \\
\hline & $25.0-29.9$ & 2665 & $1,714,191$ & 155.47 & $0.79(0.68,0.91)$ & $1.21(1.04,1.41)$ \\
\hline & $\geq 30$ & 63 & 47,291 & 133.22 & $0.68(0.52,0.90)$ & $1.21(0.89,1.62)$ \\
\hline \multirow[t]{5}{*}{$95 \leq W C$} & $<18.5$ & 0 & 0 & 0 & - & - \\
\hline & $18.5-22.9$ & 23 & 14,442 & 159.26 & Ref. & Ref. \\
\hline & $23.0-24.9$ & 198 & 85,297 & 232.13 & $1.47(0.96,2.27)$ & $1.68(1.07,2.64)$ \\
\hline & $25.0-29.9$ & 1841 & $1,020,521$ & 180.39 & $1.19(0.79,1.80)$ & $1.69(1.09,2.61)$ \\
\hline & $\geq 30$ & 382 & 272,054 & 140.41 & $0.95(0.63,1.45)$ & $1.61(1.04,2.51)$ \\
\hline
\end{tabular}

$B M I$ body mass index, WC waist circumference, $H R$ hazard ratio

${ }^{a}$ All rates are expressed as number per 100,000 person-years

${ }^{\mathrm{b}}$ Adjusted for age

${ }^{\mathrm{c} A d j u s t e d}$ for age, diabetes, hypertension, dyslipidemia, smoking status, and alcohol consumption 


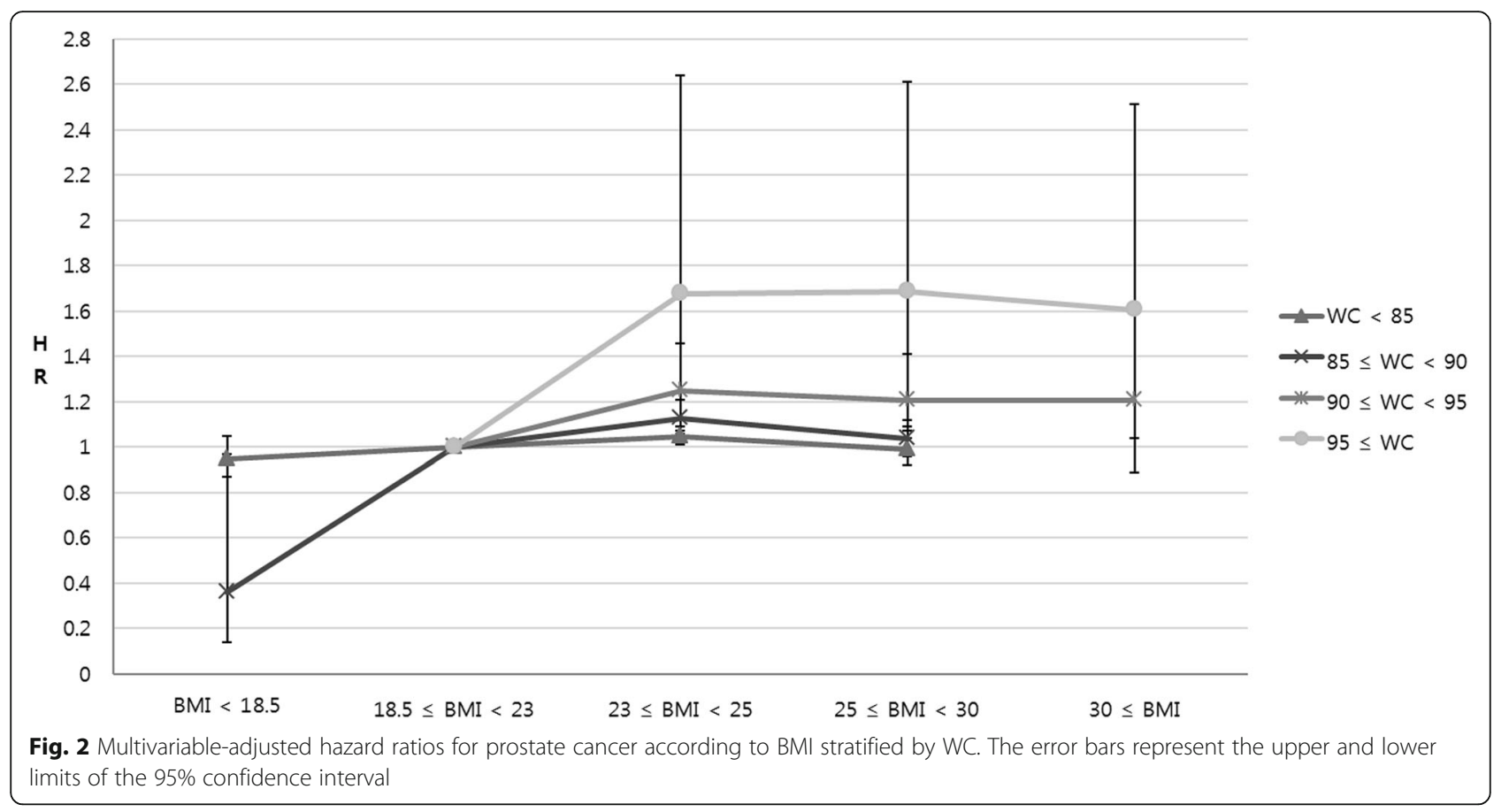

Table 4 Age- and multivariable-adjusted HRs for prostate cancer according to WC stratified by BMI

\begin{tabular}{|c|c|c|c|c|c|c|}
\hline \multirow[b]{2}{*}{$\mathrm{BMl}, \mathrm{kg} / \mathrm{m}^{2}$} & \multirow[b]{2}{*}{$W C, c m$} & \multirow[b]{2}{*}{ Event } & \multirow[b]{2}{*}{ Person-years } & \multirow[b]{2}{*}{ Incidence ${ }^{a}$} & \multicolumn{2}{|c|}{ HR (95\% confidence interval) } \\
\hline & & & & & Model $1^{\mathrm{b}}$ & Model $2^{c}$ \\
\hline \multirow[t]{4}{*}{$<18.5$} & $W C<85$ & 462 & 318,733 & 144.95 & Ref. & Ref. \\
\hline & $85 \leq W C<90$ & 4 & 4018 & 99.55 & $0.47(0.18,1.26)$ & $0.48(0.18,1.27)$ \\
\hline & $90 \leq W C<95$ & 0 & 0 & 0 & - & - \\
\hline & $95 \leq W C$ & 0 & 0 & 0 & - & - \\
\hline \multirow[t]{4}{*}{$18.5-22.9$} & $W C<85$ & 6033 & $4,138,307$ & 145.75 & Ref. & Ref. \\
\hline & $85 \leq W C<90$ & 1086 & 594,059 & 182.81 & $1.16(1.09,1.24)$ & $1.12(1.05,1.20)$ \\
\hline & $90 \leq W C<95$ & 196 & 94,269 & 207.91 & $1.14(0.99,1.31)$ & $1.03(0.89,1.20)$ \\
\hline & $95 \leq W C$ & 23 & 14,442 & 159.26 & $0.81(0.54,1.22)$ & $0.72(0.47,1.11)$ \\
\hline \multirow[t]{4}{*}{$23.0-24.9$} & $W C<85$ & 2874 & $2,046,401$ & 140.44 & Ref. & Ref. \\
\hline & $85 \leq W C<90$ & 2638 & $1,544,705$ & 170.78 & $1.08(1.03,1.15)$ & $1.09(1.03,1.15)$ \\
\hline & $90 \leq W C<95$ & 1065 & 542,265 & 196.39 & $1.04(0.97,1.12)$ & $1.05(0.98,1.13)$ \\
\hline & $95 \leq W C$ & 198 & 85,297 & 232.13 & $0.99(0.86,1.15)$ & $0.98(0.85,1.14)$ \\
\hline \multirow[t]{4}{*}{$25.0-29.9$} & $W C<85$ & 904 & 703,159 & 128.56 & Ref. & Ref. \\
\hline & $85 \leq W C<90$ & 2150 & $1,601,586$ & 134.24 & $1.01(0.93,1.09)$ & $1.01(0.93,1.09)$ \\
\hline & $90 \leq W C<95$ & 2665 & $1,714,191$ & 155.27 & $1.04(0.96,1.12)$ & $1.03(0.95,1.11)$ \\
\hline & $95 \leq W C$ & 1841 & $1,020,521$ & 180.39 & $1.03(0.95,1.11)$ & $1.01(0.93,1.09)$ \\
\hline \multirow[t]{4}{*}{$\geq 30$} & $W C<85$ & 0 & 0 & 0 & - & - \\
\hline & $85 \leq W C<90$ & 0 & 0 & 0 & - & - \\
\hline & $90 \leq W C<95$ & 63 & 47,291 & 133.22 & Ref. & Ref. \\
\hline & $95 \leq W C$ & 382 & 272,054 & 140.41 & $0.93(0.71,1.21)$ & $0.92(0.69,1.21)$ \\
\hline
\end{tabular}

$B M I$ body mass index, WC waist circumference, $H R$ hazard ratio

${ }^{a}$ All rates are expressed as number per 100,000 person-years

${ }^{\mathrm{b}}$ Adjusted for age

'Adjusted for age, diabetes, hypertension, dyslipidemia, smoking status, and alcohol consumption 


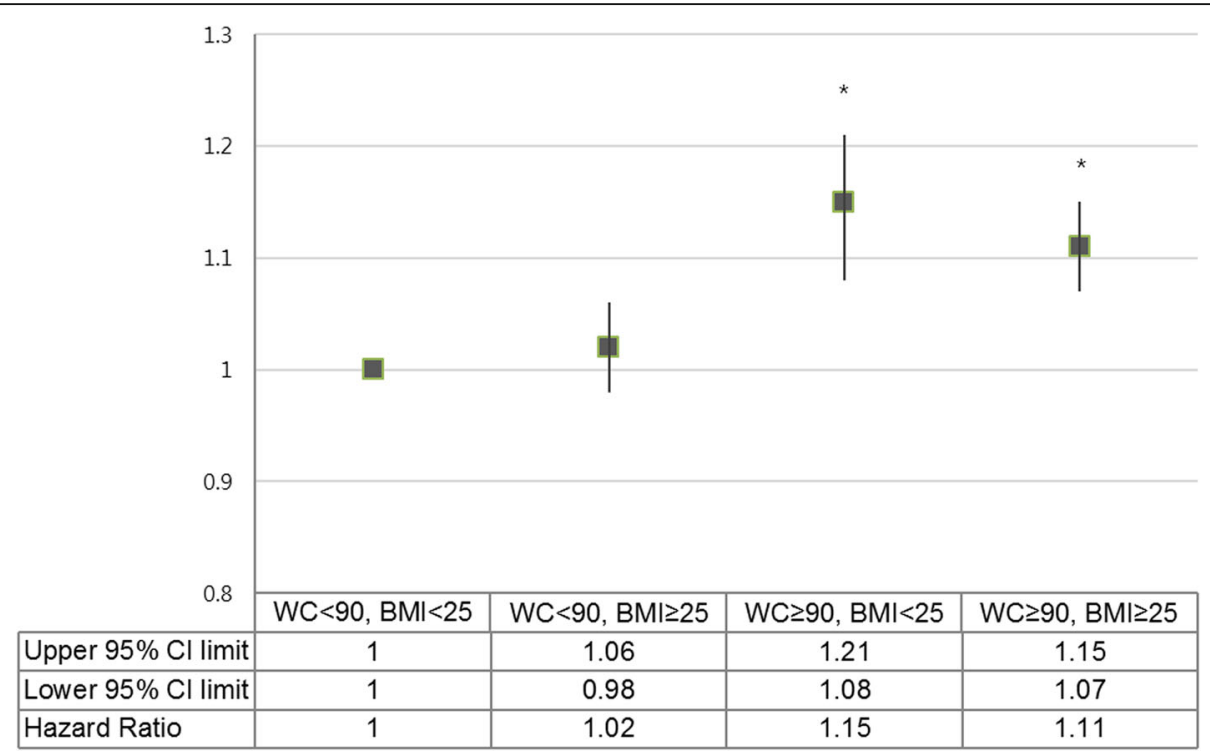

Fig. 3 Hazard ratio for prostate cancer development according to BMI (comparison of $\mathrm{BMI}<25$ and $\mathrm{BMI} \geq 25$ ) when stratified by abdominal obesity (comparison of WC $<90$ and WC $\geq 90$ ) in the age-adjusted model. The error bars represent the upper and lower limits of the $95 \%$ confidence interval. ${ }^{*} P$ value $<.001$

between Westerners and Asians [20, 21], research on evaluating risk of prostate cancer development based on obesity in Asians is necessitated.

Because obesity also affects cancer screening in various aspects, research on the relationship between obesity and cancer development is important. Increasing BMI is associated with a decrease in serum PSA, which may minimize the diagnosis of prostate cancer based on PSA screening. When considering indications for prostatic biopsy in obese men, we should be aware that the effect of hemodilution might reduce PSA levels [22, 23]. Obesity has been correlated with large prostate volume [24]. In case of larger prostate volume, it becomes difficult to get a diagnosis of prostate cancer in the same number of samples. Additionally, with adiposity impeding physical examinations, obese men may face difficulties in undergoing a DRE due to body habitus hindering prostate access [25]. Chu et al. reported that the predictive value of DRE is dependent on obesity and is significantly higher among obese men than normal-weight men [26]. Because DRE may be limited by adiposity in obese men, cancers that are large enough to be palpable may be more meaningful. Consequently, the clinician should remind these effects during the diagnostic process in patients with high BMI or high WC.

The major limitation of our study is that detailed information, such as digital rectal examination (DRE) finding, serum PSA level, prostate volume, cancer stage, Gleason grade, and molecular pathology, were not available for this nationwide cohort; thus, we could not adjust for these factors. The treatment patterns and the overall prognosis differed among regionally localized intermediate, high, and very high-risk prostate cancer. In addition, as previous studies have reported different effects of obesity [15-17], failure to perform stage analysis is an important limitation of our study. Therefore, detailed information should be thoroughly considered in future etiologic research.

\section{Conclusions}

Without considering WC as an adjustment factor, very weak association between BMI and prostate cancer development risk was observed. However, when we considered WC as an adjustment factor, in the groups with abdominal obesity, significant linear relationship was observed between increasing BMI and prostate cancer risk, and the higher the WC category, the stronger association with BMI was noted. This means that the association of BMI with risk of prostate cancer development depends on abdominal obesity. Therefore, WC should be mutually estimated while considering obesity as a risk factor of prostate cancer development.

\section{Abbreviations}

BMI: Body mass index; WC: Waist circumference; NHIS: National Health Insurance System; PSA: Prostate-specific antigen; DRE: Digital rectal examination

\section{Acknowledgements}

None.

Authors' contributions

JBC, JPM, and USH conceived and designed the experiments. JBC, JPM, and JHK performed the experiments. IAK and SHH were involved in samples recruitment. IAK and YHL analyzed the data. JBC and JPM wrote the first 
draft of the manuscript. All authors reviewed and edited the manuscript and approved the final version of the manuscript.

\section{Funding}

This study was not supported by any funding.

\section{Availability of data and materials}

The data supporting the findings of this study are available from National Health Insurance Sharing Service (https://nhiss.nhis.or.kr) in Korea, but are not publicly available due to restrictions on the availability of the materials used under the permission of this study.

\section{Ethics approval and consent to participate}

This protocol was approved by the Institutional Review Board of The Hanyang University of Korea (No. HYU-2019-01-027). After the National Health Insurance Service review committee reviewed the ethics approval and research proposal, we had the permission to use the NHIS data. Informed consent was waived because anonymous and de-identified information was used for analysis.

\section{Consent for publication}

Not applicable.

\section{Competing interests}

The authors declare no competing interests.

\section{Author details}

'Department of Urology, Bucheon St. Mary's Hospital, College of Medicine, The Catholic University of Korea, Seoul, South Korea. ${ }^{2}$ Department of Occupational and Environmental Medicine, Seoul St. Mary's Hospital, College of Medicine, The Catholic University of Korea, Seoul, South Korea.

${ }^{3}$ Department of Occupational and Environmental Medicine, Hanyang University College of Medicine, Seoul, South Korea. ${ }^{4}$ Department of Urology, Dongnam Institute of Radiological \& Medical Sciences, Cancer Center, Busan, South Korea. ${ }^{5}$ Department of Urology, Seoul St. Mary's Hospital, College of Medicine, The Catholic University of Korea, 222, Banpo-daero, Seocho-gu, Seoul 06591, South Korea.

Received: 12 February 2020 Accepted: 18 June 2020

\section{Published online: 23 June 2020}

\section{References}

1. Bray F, Ferlay J, Soerjomataram I, Siegel RL, Torre LA, Jemal A. Global cancer statistics 2018: GLOBOCAN estimates of incidence and mortality worldwide for 36 cancers in 185 countries. CA Cancer J Clin. 2018;68(6):394-424.

2. Rawla P. Epidemiology of prostate Cancer. World J Oncol. 2019;10(2):63-89.

3. Taitt HE. Global trends and prostate Cancer: a review of incidence, detection, and mortality as influenced by race, ethnicity, and geographic location. Am J Mens Health. 2018;12(6):1807-23.

4. Jung KW, Won YJ, Kong HJ, Lee ES. Cancer statistics in Korea: incidence, mortality, survival, and prevalence in 2016. Cancer Res Treat. 2019;51(2):41730.

5. Han HH, Park JW, Na JC, Chung BH, Kim CS, Ko WJ. Epidemiology of prostate cancer in South Korea. Prostate Int. 2015:3(3):99-102.

6. Park J, Cho SY, Lee SB, Son H, Jeong H. Obesity is associated with higher risk of prostate cancer detection in a biopsy population in Korea. BJU Int. 2014;114(6):891-5.

7. Allott EH, Masko EM, Freedland SJ. Obesity and prostate cancer: weighing the evidence. Eur Urol. 2013:63(5):800-9.

8. Cao Y, Giovannucci E. Obesity and prostate Cancer. Recent Results Cancer Res. 2016;208:137-53.

9. Maclnnis RJ, English DR. Body size and composition and prostate cancer risk: systematic review and meta-regression analysis. Cancer Causes Control. 2006;17(8):989-1003.

10. Renehan AG, Tyson M, Egger M, Heller RF, Zwahlen M. Body-mass index and incidence of cancer: a systematic review and meta-analysis of prospective observational studies. Lancet. 2008;371(9612):569-78.

11. Okorodudu DO, Jumean MF, Montori VM, Romero-Corral A, Somers VK, Erwin PJ, Lopez-Jimenez F. Diagnostic performance of body mass index to identify obesity as defined by body adiposity: a systematic review and meta-analysis. Int J Obes. 2010;34(5):791-9.
12. Romero-Corral A, Somers VK, Sierra-Johnson J, Thomas RJ, Collazo-Clavell ML, Korinek J, Allison TG, Batsis JA, Sert-Kuniyoshi FH, Lopez-Jimenez F. Accuracy of body mass index in diagnosing obesity in the adult general population. Int J Obes. 2008:32(6):959-66.

13. Cheol Seong S, Kim YY, Khang YH, Heon Park J, Kang HJ, Lee H, Do CH, Song JS, Hyon Bang J, Ha S, et al. Data resource profile: the National Health Information Database of the National Health Insurance Service in South Korea. Int J Epidemiol. 2017;46(3):799-800.

14. Choi JB, Kim JH, Hong SH, Han KD, Ha US. Association of body mass index with bladder cancer risk in men depends on abdominal obesity. World J Urol. 2019;37(11):2393-400.

15. Gong Z, Neuhouser ML, Goodman PJ, Albanes D, Chi C, Hsing AW, Lippman SM, Platz EA, Pollak MN, Thompson IM, et al. Obesity, diabetes, and risk of prostate cancer: results from the prostate cancer prevention trial. Cancer Epidemiol Biomarkers Prev. 2006;15(10):1977-83.

16. Rodriguez C, Freedland SJ, Deka A, Jacobs EJ, McCullough ML, Patel AV, Thun MJ, Calle EE. Body mass index, weight change, and risk of prostate cancer in the Cancer prevention study II nutrition cohort. Cancer Epidemiol Biomarkers Prev. 2007;16(1):63-9.

17. Discacciati A, Orsini N, Wolk A. Body mass index and incidence of localized and advanced prostate cancer--a dose-response meta-analysis of prospective studies. Ann Oncol. 2012;23(7):1665-71.

18. Fowke JH, Motley SS, Concepcion RS, Penson DF, Barocas DA. Obesity, body composition, and prostate cancer. BMC Cancer. 2012;12:23.

19. Guerrios-Rivera L, Howard L, Frank J, De Hoedt A, Beverly D, Grant DJ, Hoyo C, Freedland SJ. Is body mass index the best adiposity measure for prostate Cancer risk? Results from a veterans affairs biopsy cohort. Urology. 2017;105: 129-35.

20. Deurenberg P, Deurenberg-Yap M, Guricci S. Asians is different from Caucasians and from each other in their body mass index/body fat percent relationship. Obes Rev. 2002;3:141-6.

21. Wang D, Li Y, Lee SG, Wang L, Fan J, Zhang G, Wu J, Ji Y, Li S. Ethnic differences in body composition and obesity related risk factors: study in Chinese and white males living in China. PLoS One. 2011;6(5):e19835.

22. Kubota Y, Seike K, Maeda S, Shinohara Y, Iwata M, Sugimoto N. Relationship between prostate-specific antigen and obesity in prostate cancer screening: analysis of a large cohort in Japan. Int J Urol. 2011;18(1):72-5.

23. Li F, Yin X, Li D, Yin Z, Qi S, Shi H, Gao J, Zhang X. Association between obesity-related plasma hemodilution and the concentration of prostate specific antigen. Nan Fang Yi Ke Da Xue Xue Bao. 2015;35(12):1721-4.

24. Wallner LP, Morgenstern H, McGree ME, Jacobson DJ, St Sauver JL, Jacobsen SJ, Sarma AV. The effects of body mass index on changes in prostatespecific antigen levels and prostate volume over 15 years of follow-up: implications for prostate cancer detection. Cancer Epidemiol Biomarkers Prev. 2011;20(3):501-8

25. Silk AW, McTigue KM. Reexamining the physical examination for obese patients. Jama. 2011;305(2):193-4.

26. Chu DI, De Nunzio C, Gerber L, Thomas JA 2nd, Calloway EE, Albisinni S, Senocak C, McKeever MG, Moreira DM, Tubaro A, et al. Predictive value of digital rectal examination for prostate cancer detection is modified by obesity. Prostate Cancer Prostatic Dis. 2011;14(4):346-53.

\section{Publisher's Note}

Springer Nature remains neutral with regard to jurisdictional claims in published maps and institutional affiliations.

Ready to submit your research? Choose BMC and benefit from:

- fast, convenient online submission

- thorough peer review by experienced researchers in your field

- rapid publication on acceptance

- support for research data, including large and complex data types

- gold Open Access which fosters wider collaboration and increased citations

- maximum visibility for your research: over $100 \mathrm{M}$ website views per year

At BMC, research is always in progress.

Learn more biomedcentral.com/submission 